\title{
UNDERSTANDING THE NEXUS OF INTELLECTUAL, SOCIAL AND PSYCHOLOGICAL CAPITAL TOWARDS BUSINESS INNOVATION THROUGH CRITICAL INSIGHTS FROM ORGANIZATIONAL CULTURE Ammar Ahmed ${ }^{1}$, Mahmoud Radwan Hussein AlZgool ${ }^{2}$, Zahida Abro ${ }^{3}$, Umair Ahmed ${ }^{4}$, Ubedullah Memon ${ }^{5}$ \\ ${ }^{1}$ Dept of Business Administration, Institute of Southern Punjab, Pakistan, ${ }^{2}$ Gulf University, Kingdom of Bahrain, ${ }^{3}$ SZABIST Larkana, Pakistan, ${ }^{4}$ Arab Open University, Kingdom of Bahrain, ${ }^{5}$ School of Management, Universiti Sains Malaysia, Sukkur IBA, University, Pakistan. \\ Email: 1ammar.malik419@gmail.com, ${ }^{2}$ dr.mahmoud.alzgool@gulfuniversity.edu.bh, ${ }^{3}$ abroo@1rk.szabist.edu.pk, 4 umairahm@gmail.com, ${ }^{5}$ ubedullahsom@gmail.com
}

Article History: Received on $21^{\text {st }}$ August 2019, Revised on $29^{\text {th }}$ September 2019, Published on $05^{\text {th }}$ November 2019

\begin{abstract}
Purpose of Study: The paper sheds lights on the idea of business innovation through pouring scholarly review of the literature. The papers objects to provide scholars enthusiastic about business innovation to understand how intellectual, social and psychological capital can be of prominence and the acute role organizational culture can play to further it.
\end{abstract}

Methodology: The paper has strived to advance intellectual understanding of scholars in the area through underlining the direct and indirect links between these factors to help organizational practitioners obtain competitive results for their respective organizations.

Results: The paper also outlines limited studies on these relationships thus, encouraging scholars for empirical attention in the near future.

Keywords: business innovation, organizational culture, intellectual capital, social capital, psychological capital.

\section{INTRODUCTION}

Innovation of organizations has emerged as the most favorable topic for all range of researchers from every field De Jong and Den Hartog (2010). Innovation in organization has developed many successes \& efficiencies for all stakeholders including of managers, employees and organizations itself (Yuan and Woodman, 2010). Organizations can earn many competitive advantages through ongoing innovation in their structure, marketing and products (Bergek et al., 2008).

Notably, many economies need innovation in their organizations to attain performance and success (Sharifirad, 2013). Some of the studies reveal the fact that organizational culture has key impact on business innovation \& its antecedents. There has been very less work on factors influencing innovation through knowledge and technology (Olaoye and Olanipekun, 2018; Majid and Mahmud, 2019). Accordingly, current paper is focused to examine the impact of psychological, intellectual and social capital on knowledge \& technology-based business. There might be multiple variables to know the results but these factors are directly employee related and short run in their nature instead of organizational factors those often are long run (Forsman, 2011; Ahmed and Ogalo, 2019).

\section{LITERATURE REVIEW}

\section{Business innovation}

There have been many difficult \& unsystematic environments prevailing in current organization whereby they could not achieve the desired goal due to stiff competition on products and technological developments (Dinopoulos and Syropoulos, 2007). Such concept is not limited to organizations but also applies to worldwide countries, where globalization has emerged the countries in one globe (Bruque and Moyano, 2007). In such tough competitions, only the innovation becomes the vital component to face the internal\& external contingencies (Bohlmann et al., 2013; Oluwaseun and Boboye, 2017). Therefore, such companies can only survive \& create competitive advantage over competitors who adopt continuous innovation strategy as the matter of policy for organization. There have been many definitions pertaining to the concept of innovation. The early definitions considered the development or purchase as innovation of new devices, systems, policies, programs, products or services for and/or within an organization (Damanpour, 1991). Basic one is Adopting of new devices \& technology on regularly basis is called innovation.

Recent innovation definitions, however, not only included an organization's development ofFresh concepts, but also looked at the organization's results of innovation adaptation.Innovation is therefore a broad and multifaceted structure used to enh ance a business'strategic and operational performance, including policies, strategies and approaches, processes, products, services, competitors and customers (Dumay et al., 2013).

\section{Intellectual Capital}

Intellectual Capital (IC) was also suggested as an organization's main asset for creating andimproving innovation (Elsetouh i et al., 2015; Shahani et al., 2019). Such information builds up over time and is intrinsic in the individuals, structures, systems, procedures, and databases of an organization (Sandy, 2018). Several studies examined the categorization of 
components of intellectual capital, most of which showed nearly the same results. The early classifications focused on the concept's human, structural and related aspects (Steenkamp and Hooks, 2011). Based on the explanations of Moon and Kym (2006), the concept of human capital has significant distinction from the organizational and customer capital.

Henceforth, intellectual capital refers to the knowledge, experiences and skills of people in the applied world but also includes information and dimensions related to suppliers, shareholders, stakeholders and external customers. Based on these definitions, it can be asserted that human and customer capital has some association with innovative behavior of managers. Since human capital denotes to individual`s beliefs and skills and competencies pertaining to collection of existing knowledge, relational capital demonstrates the relationship and the people such as customer satisfaction.

\section{Social Capital}

Social capital is a notion commonly used by economists, sociologists, and scientists in leadership, referring to the advantages people derive from social interactions (Akram et al., 2017). There is a powerful social capital for individuals with a multitude of social networks, links with distinct individuals and relationships with individuals from distinct backgrounds (Uslaner and Dekker, 2001; Pragati and Varsha, 2018).

For a long time, social capital has been seen as having an impact on company results and achievement. Adler and Kwon (2002) provided twenty social capital definitions to reflect conceptualization variety. The concept of social capital taken in a research relies heavily on the level of discipline and evaluation (Robison et al., 2002; Ramkumar and Rajini, 2018).

Definitions can be categorized on the basis of social capital's key components, origins and implications (Adler and Kwon, 2002). Therefore, social capital is a notion that is extremely context-specific and multidimensional, representing the benefits of links and interactions (Robison et al., 2002). Empirical studies have demonstrated that social capital has an impact on organizational development procedures (Moran, 2005). Recent study also identified the important and positive effect of social organizational assets (i.e., structural, relational and cognitive) on the creative work behavior of staff in tiny companies (Akram et al., 2017).

In the service industries, the connection between social capital and managers ' creative conduct was also suggested (Elsetouhi et al., 2015). The value generated for individuals and organizations by networks and interactions is at the core of social capital, which brings together distinct people (Tata and Prasad, 2015). Through these links, individuals with distinct experiences, values, abilities and backgrounds exchange their data, understanding, and thinking, conduct officially or informally, and generate fresh thoughts (Conway, 1995; Ramkumar and Rajini, 2018).

\section{Psychological Capital}

Recently, policymakers, scientists and professionals have gained growing attention to the variables influencing company innovation (Saeed and Kayani, 2018). Recent study has suggested mostly psychological capital (PsyCap) as the critical strategic resource that greatly enhances an organization's development and thus efficiency (Rego et al., 2012).

PsyCap's important effect is not restricted to the level of the organisation (Luthans et al., 2007) but also includes the ability of staff to innovate by affecting their attitudes, actions and performance (Tahir et al., 2019). In this sense, PsyCap is a type of capacity that distinguishes individuals from other human-related qualities (e.g. human and social capitals). Importantly, it is possible to evaluate and develop PsyCap to promote employee innovation behavior (Ross, 2018). Previous research proposed four major resources derived from the positive literature on psychology and shaped the development of staff (Romina, 2018). The development of employees represents their self-efficacy, hope, optimism and resilience in the creation and implementation of fresh concepts.

A main element of social cognitive theory is self-efficacy (Bandura, 2012). Self-efficacy represents the perceived abilities of those who are able to conduct a job effectively and attain a objective in a specific environment (Ramkumar and Rajini, 2018). Individuals with elevated self-efficacy have the ability to direct the effects of their actions and overcome the complicated difficulties of their job performance system (Bandura, 1997). As highlighted by Scheier et al. (2001), optimism demonstrates the expectation of favorable results from the fulfillment of their assignment by people (Bakytgul et al., 2019). Having high optimism, people pursue their objectives with powerful conviction that their efforts lead to the required results and continue to face problems.

Accordingly, resilience indicates the ability of the individual to encounter difficulties, lack of certainty and risks, and to adapt to the challenges and complexities of life (Masten, 2002; Sandy, 2018). Therefore, in difficult environments, resilience produces good performance (Luthans et al., 2007; Ross, 2018) .

Empirical studies also suggested a significant link between PsyCap components and the innovation behavior of employees. Study by Barron and Harrington (1981) showed that trustworthy staff have better efficiency in innovation. Luthans et al. (2007) found an important relationship between the optimism and self-confidence of employees and their ability to generate and propose new ideas and put the ideas into practice.

Ramkumar and Rajini (2018) research showed that both components of PsyCap (hope, self-efficacy, optimism, and resilience) and overall psychological quality of employees affect their innovation performance. In addition, their study suggested that PsyCap significantly improves employees' innovation performance and its dimensions. PsyCap and 
particularly tolerance, courtesy, and modesty also enable employees to present and implement their new ideas with less persistence and obtain higher recognition and supports from others (Qiu et al., 2015; Saeed and Kayani, 2018).

\section{Organizational Culture and Business Innovation}

For decades, the topic of organizational culture has been deployed for the assessment of rituals, rites, beliefs and values in an organization (Schein, 2004; Peel et al., 2018). An organization's culture is the prevalent values, beliefs, standards, and processes that regulate the organization's habits and performance.

Organizational culture creates identity among an organization's members and is considered as an accepted fact mostly by the members. Watson (2006) attempted to underline the concept of culture and has asserted it as ' something cultivated ' from an organization metaphor. Several studies have highlighted the crucial role of organizational culture in innovation development.

One recent study has also shown the important impact of organizational culture on top law firms ' innovation behaviors (Maroofi, 2016). Research results have shown, in particular, that certain cultures correlate with an organization's financial performance (Sørensen, 2002; Romina, 2018). An organization with a culture of processes that is predominantly internal is more resistant to innovation.

Studies have worked and hence, reported the facilitation of organizational culture towards innovation includes developments with considerable changes. This is also in line with the arguments of O'Donovan (2008). This in the views of Moon and Kym (2006) are also important to be understand as they also referred to the idea stating that intellectual capital and organizational culture can provide an excellent interplay.

\section{CONCLUSION}

The present review-based article has conclusively outlined a critical link interplay between intellectual, social and psychological capital with business innovation. Therein, the paper has also indicated towards the role of organizational culture towards business innovation and it could be used to help enrich these relationship further.

\section{REFERENCES}

1. Adler, P.S. and S.-W. Kwon, 2002. Social capital: Prospects for a new concept. Academy of Management Review, 27(1): 17-40.Available at: https://doi.org/10.5465/amr.2002.5922314.

2. Ahmed, A. and H.S. Ogalo, 2019. From hrm to e-hrm: Contemporary developments from scholarly work. Annals of Contemporary Developments in Management \& HR, 1(1): 1-6.Available at: https://doi.org/10.33166/acdmhr.2019.01.001.

3. Akram, T., S. Lei, M.J. Haider and M.W. Akram, 2017. What impact do structural, relational and cognitive organisational social capital have on employee innovative work behaviour? A study from China. International Journal of Innovation Management, 21(02): 1750012.Available at: https://doi.org/10.1142/s1363919617500128.

4. Bakytgul, W., M. Ahmed and Y. Kim, 2019. Corporate entrepreneurship and organizational performance: The moderating role of organizational engagement. Annals of Contemporary Developments in Management \& HR, 1(1): 39-45.

5. Bandura, A., 1997. Self-efficacy: The exercise of control. Macmillan, 35(3).Available at: https://doi.org/10.5860/choice.35-1826.

6. Bandura, A., 2012. On the functional properties of perceived self-efficacy revisited. 38(1): 9-44.Available at: https://doi.org/10.1177/0149206311410606.

7. Barron, F. and D.M. Harrington, 1981. Creativity, intelligence, and personality. Annual Review of Psychology, 32(1): 439-476.

8. Bergek, A., M. Hekkert and S. Jacobsson, 2008. Functions in innovation systems: A framework for analysing energy system dynamics and identifying goals for system-building activities by entrepreneurs and policy makers. Innovation for a Low Carbon Economy: Economic, Institutional and Management Approaches, 28(7): 393407.Available at: https://doi.org/10.1016/j.technovation.2008.01.002.

9. Bohlmann, J.D., J. Spanjol, W.J. Qualls and J.A. Rosa, 2013. The interplay of customer and product innovation dynamics: An exploratory study. Journal of Product Innovation Management, 30(2): 228-244.Available at: https://doi.org/10.1111/j.1540-5885.2012.00962.x.

10. Bruque, S. and J. Moyano, 2007. Organisational determinants of information technology adoption and implementation in SMEs: The case of family and cooperative firms. Technovation, 27(5): 241-253.Available at: https://doi.org/10.1016/j.technovation.2006.12.003.

11. Conway, S., 1995. Informal boundary-spanning communication in the innovation process: An empirical study. Technology Analysis \& Strategic Management, 7(3): 327-342.Available at: https://doi.org/10.1080/09537329508524216.

12. Damanpour, F., 1991. Organizational innovation: A meta-analysis of effects of determinants and moderators. Academy of Management Journal, 34(3): 555-590.Available at: https://doi.org/10.5465/256406.

13. De Jong, J. and D. Den Hartog, 2010. Measuring innovative work behaviour. Creativity and Innovation Management, 19(1): 23-36.Available at: https://doi.org/10.1111/j.1467-8691.2010.00547.x. 
14. Dinopoulos, E. and C. Syropoulos, 2007. Rent protection as a barrier to innovation and growth. Economic Theory, 32(2): 309-332.Available at: https://doi.org/10.1007/s00199-006-0124-4.

15. Dumay, J., J. Rooney and L. Marini, 2013. An intellectual capital-based differentiation theory of innovation practice. Journal of Intellectual Capital, 14(4): 608-633.Available at: https://doi.org/10.1108/jic-02-2013-0024.

16. Elsetouhi, A., I. Elbeltagi and M.Y. Haddoud, 2015. Intellectual capital and innovations: Is organisational capital a missing link in the service sector? International Journal of Innovation Management, 19(02): 1550020.Available at: https://doi.org/10.1142/s1363919615500206.

17. Forsman, H., 2011. Innovation capacity and innovation development in small enterprises. A comparison between the manufacturing and service sectors. Research Policy, 40(5): 739-750.Available at: https://doi.org/10.1016/j.respol.2011.02.003.

18. Luthans, F., C.M. Youssef and B.J. Avolio, 2007. Psychological capital: Developing the human competitive edge.

19. Majid, M.B. and M.S. Mahmud, 2019. Knowledge management and its impact on organizational performance: Evidence from Pakistan. Annals of Contemporary Developments in Management \& HR, 1(1): 7-14.Available at: https://doi.org/10.33166/acdmhr.2019.01.002.

20. Maroofi, F., 2016. Investigating the links between the distinct layers of an organization's culture and innovative behaviours. International Journal of Innovation Management, 20(7): 1-28.Available at: https://doi.org/10.1142/s1363919616500729.

21. Masten, A.S., 2002. Resilience in development. Handbook of Positive Psychology, 74: 88.

22. Moon, Y.J. and H.G. Kym, 2006. A model for the value of intellectual capital. Canadian Journal of Administrative Sciences, 23(3): 253-269.

23. Moran, P., 2005. Structural vs. Relational embeddedness: Social capital and managerial performance. Strategic Management Journal, 26(12): 1129-1151.Available at: https://doi.org/10.1002/smj.486.

24. O'Donovan, G., 2008. The corporate culture handbook: How to plan, implement and measure a successful culture change programme. Development and Learning in Organizations: An International Journal, 22(1).Available at: https://doi.org/10.1108/dlo.2008.08122aae.001.

25. Olaoye, C.O. and C.T. Olanipekun, 2018. Impact of forensic accounting and investigation on corporate governance in Ekiti State. Journal of Accounting, Business and Finance Research, 4(1): 28-36.

26. Oluwaseun, G.O. and L.A. Boboye, 2017. Randomness of stock return in Nigerian banking sector. Asian Journal of Economics and Empirical Research, 4(2): 99-105.

27. Peel, R., N. Caltabiano, B. Buckby and K. McBain, 2018. Mental health diagnoses and relationship breakdown: Which is the chicken and which the egg? International Journal of Innovation, Creativity and Change, 4(3): 98116.

28. Pragati, S. and D. Varsha, 2018. Employee engagement, work autonomy and innovative work behaviour: An empirical study. International Journal of Innovation, Creativity and Change, 4(2): 158-175.

29. Qiu, X., X. Yan and Y. Lv, 2015. The effect of psychological capital and knowledge sharing on innovation performance for professional technical employees. Journal of Service Science and Management, 8(4): 545551.Available at: https://doi.org/10.4236/jssm.2015.84055.

30. Ramkumar, A. and G. Rajini, 2018. Innovative human resource practices and selected H.R. Outcomes in software firms. International Journal of Innovation, Creativity and Change, 4(2): 134-157.

31. Ramkumar, A. and G. Rajini, 2018. Personality and success level prediction of individuals using soft skills measures and its performance evaluation. International Journal of Innovation, Creativity and Change, 4(1): 112131.

32. Rego, A., F. Sousa, C. Marques and M.P.E. Cunha, 2012. Authentic leadership promoting employees psychological capital and creativity. Journal of Business Research, 65(3): 429-437.Available at: https://doi.org/10.1016/j.jbusres.2011.10.003.

33. Robison, L.J., A.A. Schmid and M.E. Siles, 2002. Is social capital really capital? Review of Social Economy, 60(1): 1-21.Available at: https://doi.org/10.1080/00346760110127074.

34. Romina, C.E., 2018. Serious leisure, self-perceptions and everyday creativity. International Journal of Innovation, Creativity and Change, 4(1): 52-73.

35. Ross, W.P., 2018. Art-led communitas for developing improved mental health in higher education in a time of rapid change. International Journal of Innovation, Creativity and Change, 4(3): 125-141.

36. Saeed, N. and A.I. Kayani, 2018. Role of college principals in promoting quality of education in District Kotli AJ\&K. Asian Journal of Contemporary Education, 2(2): 149-158.

37. Sandy, W., 2018. Factors influencing Indonesian students satisfaction during their studies in China. Asian Journal of Contemporary Education, 2(2): 136-148.

38. Scheier, M.F., C.S. Carver and M.W. Bridges, 2001. Optimism, pessimism, and psychological well-being. Optimism and Pessimism: Implications for Theory, Research, and Practice, 1: 189-216.

39. Schein, E.H., 2004. Organizational culture and leadership. 3rd Edn., San Francisco: Jossey Bass.

40. Shahani, N.N., M. Nawaz and N. Dharejo, 2019. Two facets of organizational politics, the constructive and destructive role of organizational politics on employee work related attitudes: A theoretical study. Annals of Contemporary Developments in Management \& HR, 1(1): 15-22.Available at: https://doi.org/10.33166/acdmhr.2019.01.003. 
41. Sharifirad, M.S., 2013. Transformational leadership, innovative work behavior, and employee well-being. Global Business Perspectives, 1(3): 198-225.Available at: https://doi.org/10.1007/s40196-013-0019-2.

42. Sørensen, J.B., 2002. The strength of corporate culture and the reliability of firm performance. Administrative Science Quarterly, 47(1): 70-91.Available at: https://doi.org/10.2307/3094891.

43. Steenkamp, N. and J. Hooks, 2011. Does including pictorial disclosure of intellectual capital resources make a difference? Pacific Accounting Review, 23(1): 52-68.Available at: https://doi.org/10.1108/01140581111130661.

44. Tahir, R., M.R. Athar, F. Faisal, N.N. Shahani and B. Solangi, 2019. Green organizational culture: A review of literature and future research agenda. Annals of Contemporary Developments in Management \& HR, 1(1): 2338.Available at: https://doi.org/10.33166/acdmhr.2019.01.004.

45. Tata, J. and S. Prasad, 2015. National cultural values, sustainability beliefs, and organizational initiatives. Cross Cultural Management, 22(2): 278-296.Available at: https://doi.org/10.1108/ccm-03-2014-0028.

46. Uslaner, E.M. and P. Dekker, 2001. The social of social capital. Social Capital and Participation in Everyday Life: 176-187.

47. Watson, T.J., 2006. Organising and managing work: Organisational, managerial and strategic behaviour in theory and practice. Pearson Education.

48. Yuan, F. and R.W. Woodman, 2010. Innovative behavior in the workplace: The role of performance and image outcome expectations. Academy of Management Journal, 53(2): 323-342.Available at: https://doi.org/10.1108/dlo.2010.08124fad.010. 